ARTICLE

Received 26 Jun 2014 | Accepted 7 Aug 2015 | Published 14 Sep $2015 \quad$ DOl: 10.1038/ncomms9298

\title{
Seismic evidence of a two-layer lithospheric deformation in the Indian Ocean
}

Yanfang $\operatorname{Qin}^{1} \&$ Satish C. Singh ${ }^{1}$

Intra-plate deformation and associated earthquakes are enigmatic features on the Earth. The Wharton Basin in the Indian Ocean is one of the most active intra-plate deformation zones, confirmed by the occurrence of the 2012 great earthquakes $(M w \geq 8.2)$. These earthquakes seem to have ruptured the whole lithosphere, but how this deformation is distributed at depth remains unknown. Here we present seismic reflection images that show faults down to $45 \mathrm{~km}$ depth. The amplitude of these reflections in the mantle first decreases with depth down to $25 \mathrm{~km}$ and then remains constant down to $45 \mathrm{~km}$. The number of faults imaged along the profile and the number of earthquakes as a function of depth show a similar pattern, suggesting that the lithospheric mantle deformation can be divided into two layers: a highly fractured fluid-filled serpentinized upper layer and a pristine brittle lithospheric mantle where great earthquakes initiate and large stress drops occur.

\footnotetext{
${ }^{1}$ Equipe de Géosciences Marines, Institut de Physique du Globe de Paris (CNRS, Paris Diderot, Sorbonne Paris Cité), 1 rue Jussieu, Paris 75238, France. Correspondence and requests for materials should be addressed to S.C.S. (email: singh@ipg..fr).
} 
T he Indian Ocean Basin is one of the most active intra-plate deformation zones on the Earth ${ }^{1-5}$. The deformation is due to the differential rate of subduction/collision of the Indo-Australian plate beneath the Eurasia and Sunda plates. The deformation seems to have initiated $\sim 15 \mathrm{Ma} \mathrm{ago}{ }^{6}$ and was enhanced around $8 \mathrm{Ma}$ ago when the Tibetan plateau attained its maximum elevation ${ }^{7}$. The weak rheology of the Ninety East Ridge (NER) acts as a boundary for strain orientation and deformation style ${ }^{5,8,9}$, causing different types of deformation in the Central Indian Basin (CIB) and the Wharton Basin (WB). To the west of the NER in the CIB, deformation is taking place along E-W trending high-angle thrust faults and associated folds ${ }^{1-3}$ due to the N-S compression resulting from the continental collision of India with Eurasia. To the east of the NER in the $\mathrm{WB}$, the direction of the maximum stress is NW-SE, and the deformation is accommodated along $\mathrm{N}^{\circ} \mathrm{E}$-trending re-activated fracture zones with left-lateral strike-slip movements $\mathrm{s}^{2,5,10,11}$. This was recently confirmed by the occurrence of the $\mathrm{Mw}=8.6$ earthquake on April 11, 2012 in the WB, the largest strike-slip earthquake ever observed on the Earth. It was preceded by a foreshock of $\mathrm{Mw}=7.2$ on January 10, 2012 and followed by an aftershock of $\mathrm{Mw}=8.2$ (ref. 12) along with many small aftershocks, suggesting that the $\mathrm{WB}$ is indeed deforming actively.

The lithosphere in the $\mathrm{WB}$ was created at the Wharton Spreading Centre (WSC) between 133 and $40 \mathrm{Ma}$ ago ${ }^{13,14}$. A major reorganization of the Indian Ocean ridge system occurred following the initial collision of India with Eurasia $\sim 50 \mathrm{Ma}$ ago and the cessation of spreading at the WSC around $40 \mathrm{Ma}$ ago, after which India and Australia became a single plate. Present-day intra-plate left-lateral deformation in the WB is consistent with the increasing obliquity and decreasing convergence rate of the Indo-Australian plate from Java (orthogonal at $60 \mathrm{~mm} \mathrm{yr}^{-1}$ ) in the east to Sumatra $\left(54 \mathrm{~mm} \mathrm{yr}^{-1}\right)$ in the west, and nearly arc-parallel near the Andaman Islands $\left(43 \mathrm{~mm} \mathrm{yr}^{-1}\right)^{15}$.

Based on bathymetry and shallow seismic data, Deplus et al. ${ }^{5}$ suggested that the differential motion in the $\mathrm{WB}$ is accommodated along re-activated $\mathrm{N} 5^{\circ} \mathrm{E}$ trending fracture zones although NE-SW lineation gravity indicates some folding ${ }^{5,16}$. Most of the earthquakes in the WB have left-lateral strike-slip motion, with a few earthquakes having normal or thrust motions (Fig. 1). Based on waveform analyses, Robinson et al. ${ }^{17}$ suggested that the $2000 \mathrm{Mw}=7.9$ Cocos earthquake did not only rupture a re-activated $\mathrm{N} 5^{\circ} \mathrm{E}$ fracture zone but possibly also an orthogonal $\mathrm{E}-\mathrm{W}$ trending ridge parallel fault. Some active thrust faults are also reported with an orientation perpendicular to the NW-SE compressive axis ${ }^{10}$. The 10 January foreshock $(\mathrm{Mw}=7.2)$ and 11 April aftershock $(\mathrm{Mw}=8.2)$ seem to have ruptured the re-activated fracture F6 (Fig. 1), but the slip during the $\mathrm{Mw}=8.6$ earthquake is more complex, involving several near-orthogonal fault segments ${ }^{12,18,19}$. While some authors argue that only the NNE-SSW fault plane along a fracture zone (F6) (Fig. 1) was re-activated ${ }^{20}$, some others suggest that new lithospheric faults, not the existing fabric, were initiated ${ }^{18}$.

A marine seismic survey was conducted offshore northern Sumatra in 2006 to investigate the structural properties of the Sumatra subduction zone ${ }^{21}$. Our study area is located $\sim 100 \mathrm{~km}$ north of the 2012 main shock, close to the 10 January foreshock. We focus on a 233-km-long trench-parallel seismic profile (WG3) and a small segment of the orthogonal profile WG2 (Fig. 1). Profile WG3 runs between 32 and $66 \mathrm{~km}$ from the subduction front over a $55-58 \mathrm{Ma}$ old oceanic crust ${ }^{22}$ (Fig. 1). Using these data, we describe the shallow deformation and their link with deep mantle faults, and shed light upon the nature of the lithospheric deformation in the WB.

The seismic image shows dipping reflections down to $45 \mathrm{~km}$ depth, which we interpret as deep penetrating mantle faults. The

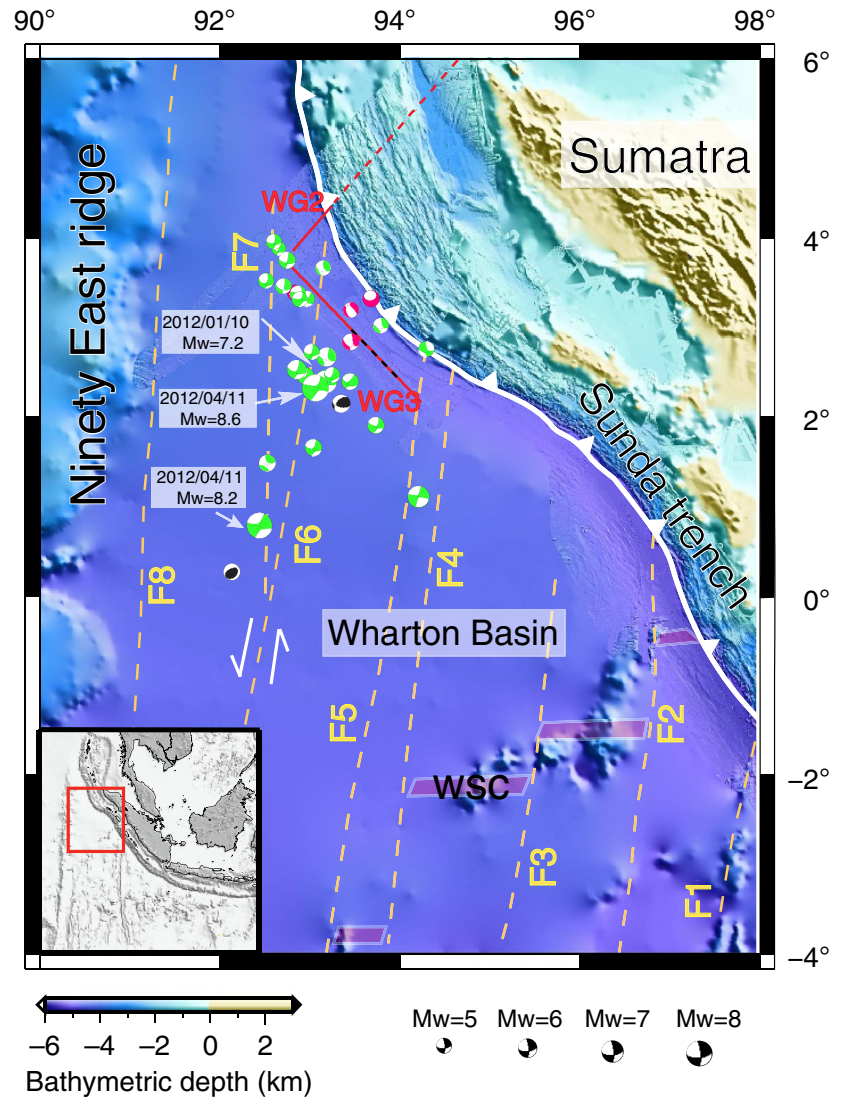

Figure 1 | Study Area. The red lines indicate the seismic profiles WG3 and WG2, with solid lines showing the part of the profiles used in this study. The black dashed line indicates the portion of the seismic image shown in Fig. 4. Yellow dashed lines indicate the fracture zones marked by F1-F8. WSC: Wharton Spreading Centre. The beach balls indicate earthquakes with $\mathrm{Mw} \geq 4.8$ that have a CMT solution in the area where the lithosphere is $\sim 56$ to 60 Ma old (see Table 2). Normal: Red, Strike-slip: Green, Thrust: Black. The red rectangle in the insert indicates the location of the study area. The locations of the three 2012 earthquakes discussed in the text are also marked.

number of faults first decreases with depth down to $25-30 \mathrm{~km}$ and then remains constant down to $45 \mathrm{~km}$ depth. The relative amplitudes of these reflections also first decrease with depth down to $25 \mathrm{~km}$ and then remain constant down to the base of the lithosphere. A similar behaviour is observed for a number of earthquakes originating in the mantle. These results suggest that the deformation in the mantle consists of two layers, an upper serpentinite layer (SL) where a large number of earthquakes occur and a pristine layer (PL) where great earthquakes initiate and large stress drops occur. The boundary between the SL and PL is likely to be responsible for the presence of the double Bennioff Zone observed in subudction zones worldwide.

\section{Results}

Shallow structures. The deep seismic reflection profile WG3 crosses the northern extremity of one of the fault segments of the $2012 \mathrm{Mw}$ 8.6 WB intra-plate strike-slip earthquake. The entire WG3 seismic image in the two-way-travel time domain is shown in Fig. 2a and its interpreted line drawing is shown in Fig. 2b. We depth converted the seismic image (Supplementary Fig. 1) using a one-dimensional velocity (Supplementary Fig. 2) determined from a combination of seismic tomography acquired along an 

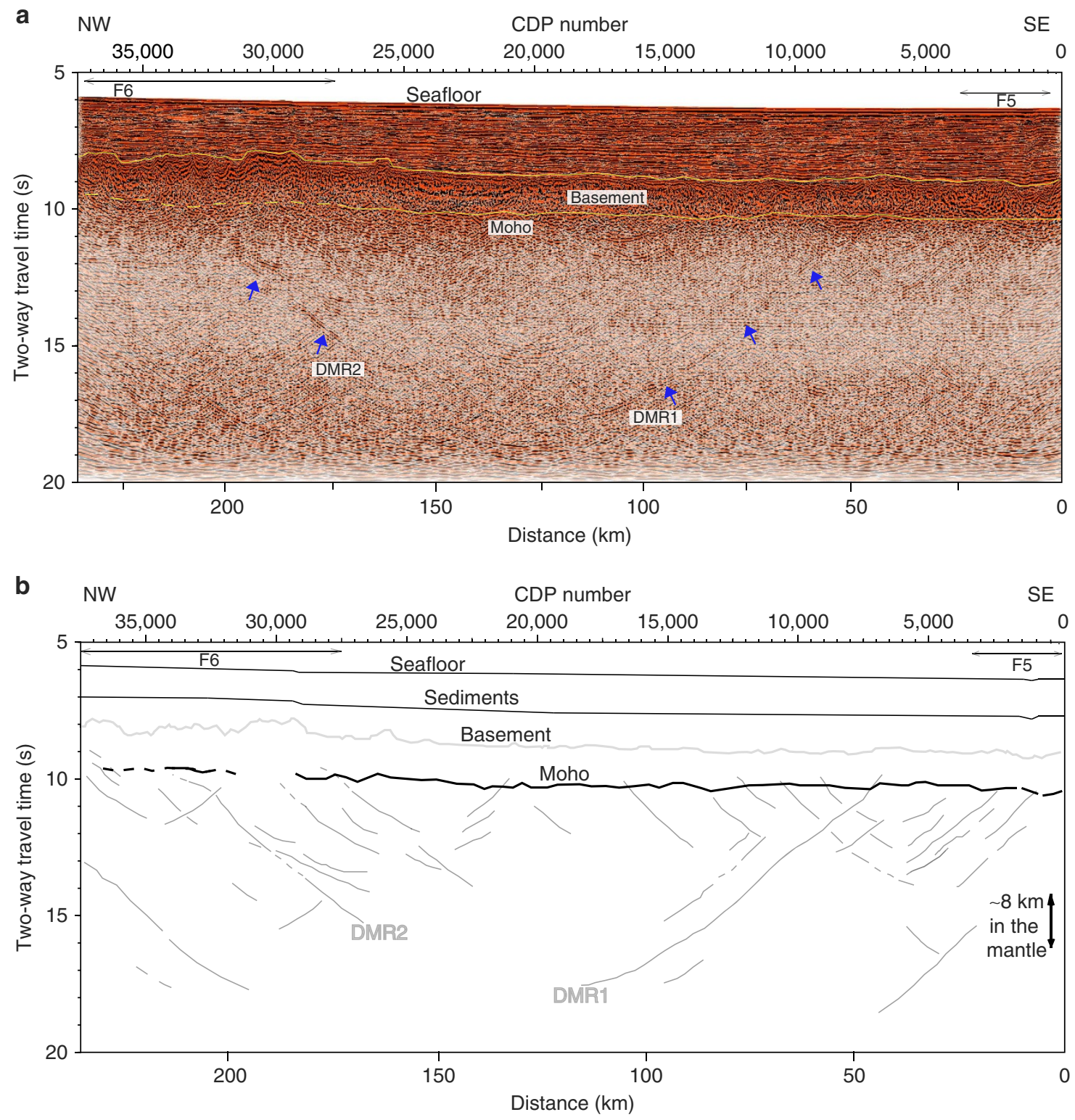

Figure 2 | Time Seismic image and interpreted faults. (a) Post-stack time domain migrated seismic reflection image along profile WG3. F5 and F6 indicate the crossing of the fracture zones. DMR1 and DMR2 are the deep mantle reflectors. (b) Line drawing of interpreted reflections from the migrated section shown in $\mathbf{a}$.

orthogonal profile ${ }^{23}$ and mantle velocity determined for oceanic mantle formed at the fast spreading East Pacific Rise ${ }^{24}$. The details of the data acquisition and processing can be found in the Methods section. The water depth varies from $4.7 \mathrm{~km}$ in the southeast to $4.4 \mathrm{~km}$ in the northwest whereas the sediment thickness decreases from $3.5-4 \mathrm{~km}$ to $2.5-3 \mathrm{~km}$ (Supplementary Fig. 1). Most of the sediments are recent, supplied from the Nicobar fan over the last $15 \mathrm{Ma}$, and record recent tectonic history. The top of the oceanic crust and the oceanic Moho are well imaged along most of the profile (Fig. 2, Supplementary Fig. 1). The crust in this area is thin, possibly due to the ridge-plume interaction ${ }^{22}$. The ridge-plume interaction usually tends to produce a thicker crust, but it can also lead to the formation of thinner crust due to the formation of cold channels around plumes ${ }^{25,26}$ and their interaction with a spreading centre.

The profile crosses two fracture zones, F5 and F6: F5 can be identified by a depression on the seafloor and in the basement near CDP 1500 in the SE, and F6 by a $\sim 60-\mathrm{km}$ wide complex basement high starting from CDP 29000 to the end of the profile in the $\mathrm{NW}^{27}$ (Fig. 3). The faults in the sediments reaching up to the seafloor suggest that both F5 and F6 have been re-activated in the recent past. The narrow zone $(2 \mathrm{~km})$ of deformation at F5 indicates the existence of strike-slip faulting. The deformation along F6 is characterized by several eastward-dipping faults. The dip of these faults is steep, between $50^{\circ}$ and $75^{\circ}$. Bathymetry data suggest that the strike of these faults is N-S, parallel to the strike of F6 (ref. 27), suggesting the re-activation of F6 in a very broad zone. The top of the oceanic crust between F6 and F7 is dominated by complex topography $(\sim 2 \mathrm{~km}$ wide and $\sim 1 \mathrm{~km}$ high), indicating that this region is geologically complex, as indicated by the magnetic anomaly study ${ }^{28}$ and orthogonal seismic profile ${ }^{27}$. In between these two fracture zones, only lower sedimentary strata are deformed and faults initiate from the basement but do not reach the seafloor, implying that the deformation between the fracture zones ceased some time ago and most of the motion might be accommodated along these fracture zones. Since our profile is parallel to the subduction front, it would be difficult to image trench-ward dipping normal 


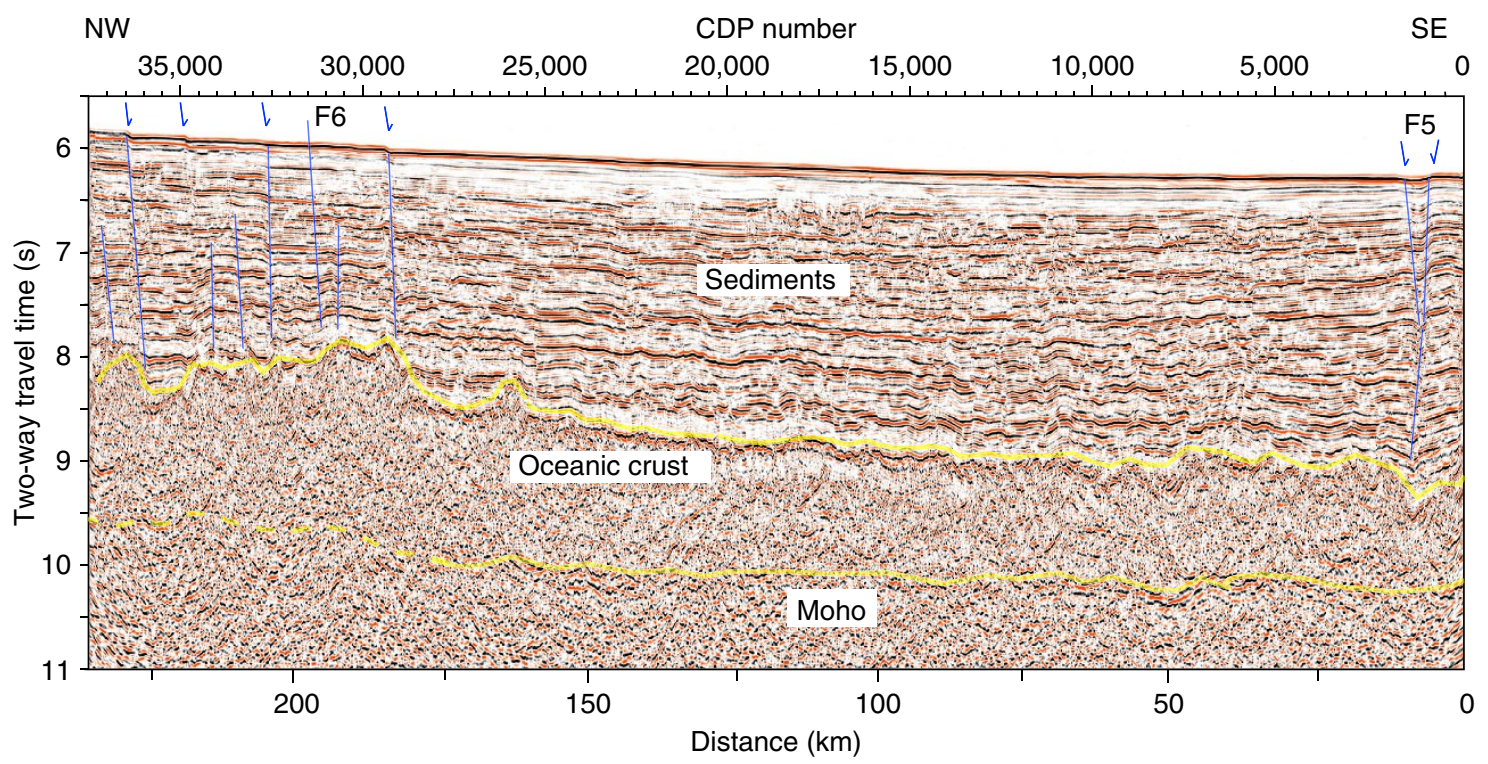

Figure 3 | Shallow part of WG3 seismic reflection image. The interpreted seismic reflection image along WG3 in the time domain. The faults in the region of the two fracture zones F5 and F6 are marked by blue lines and arrows. Yellow lines highlight the oceanic crust and the Moho.

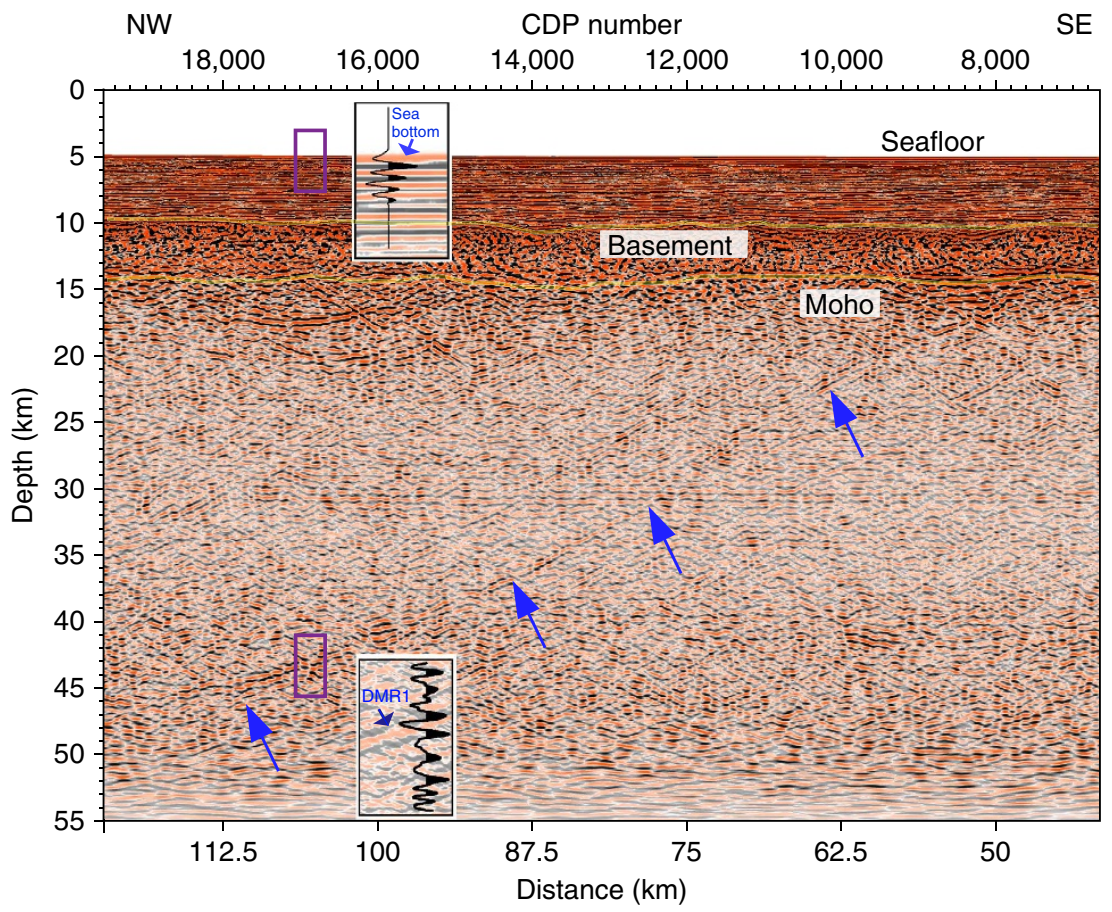

Figure 4 | Seismic reflection image of the deepest fault (DMR1). The arrows mark the position of the deep penetrating fault. The purple rectangles indicate the blow-up of seismic images and wiggle traces of the seafloor and the deep mantle reflector shown adjacent to them. An automatic gain control with a $3 \mathrm{~km}$-long window was applied to enhance the reflections at depth. For precise location of the image see Supplementary Fig. 1.

faults in the sediments, but the dip-slip motion observed over F6 might be due to bending related stress 27 .

Mantle reflections. The most striking feature in this seismic image is the presence of a large number of dipping reflectors in the mantle (Supplementary Fig. 3); one of them penetrates down to $45 \mathrm{~km}$ depth (DMR1), the deepest reflection ever imaged within the oceanic lithosphere (Fig. 4), and a second one (DMR2) extends down to $37 \mathrm{~km}$. These reflections are real and are not associated with scattering effects from the seafloor or the basement ${ }^{27}$. A pre-processed super common mid-point gather clearly shows the reflector event corresponding to the DMR1 at $17.25 \mathrm{~s}$ (Fig. 5). Although some dipping reflections are present in the crust (Supplementary Fig. 4), the dipping mantle reflections are seldom seen cutting through the crust; rather they tend to initiate near the Moho and continue down into the mantle until at least $20-30 \mathrm{~km}$, some of them up to $45 \mathrm{~km}$. The relationship between these deep reflectors and shallow deformation is unclear, as we do not observe any continuous events connecting the faults imaged in the sediments with the deep reflectors through the crust. The dip of these mantle reflections is between $25^{\circ}$ to $35^{\circ}$, 
and they dip in both directions. Although profile WG3 is not orthogonal to the oceanic fabric (E-W spreading and N-S fracture zones), we can project the two major faults (DMR1 and DMR2) to different strikes. We find that the dip of these reflections only increases to $30-45^{\circ}$ (see Methods, Supplementary Figs 5 and 6).

We estimated the polarities of deep reflections and of the seafloor by summing dozens of migrated traces on the seafloor and at different depths along the deep reflections. The results show that the polarity of the DMR1 is reverse to that of the seafloor (Fig. 4). Since the velocity increases with depth below the seafloor, the medium in the immediate vicinity of the reflector should have a lower velocity when compared to that of the surrounding bulk medium. Thus the negative polarities suggest that the deep reflections are produced by negative velocity (impedance) contrasts. The dominant frequency of these reflections is $7-10 \mathrm{~Hz}$ (Supplementary Fig. 7), hence the dominant wavelength would be $\sim 1 \mathrm{~km}$ for a mantle P-wave velocity of $8 \mathrm{~km} \mathrm{~s}^{-1}$, therefore the thickness of the reflective zone has to be at least $250-1,000 \mathrm{~m}$ in order to be imaged by a seismic method.

In order to gain more insight on these deep reflections, we show seismic images along profile WG3 and an orthogonal profile WG2 (Fig. 1), using a 3D perspective view (Fig. 6). The crustal features on the WG2 profile are similar to those observed on WG3, but a fault is seen to cut through the entire crust and connects with a fault in the sedimentary layer at the top and with a mantle reflector near the bottom, showing that crustal faults can be imaged if they are shallow dipping.

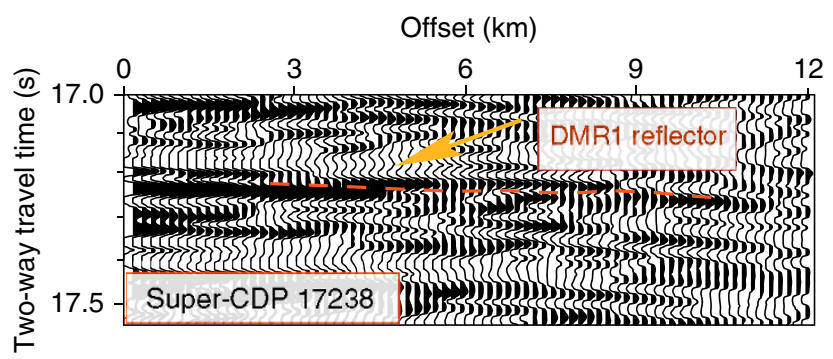

Figure 5 | Super-CDP gather. Super-CDP gather 17283 showing DMR1 reflector as a function of offset at $17.25 \mathrm{~s}$.
Depth dependence. Figure 7a and Supplementary Fig. 8 show the ratio of amplitudes of the two main dipping reflections (DMR1, DMR2) and the seafloor reflection as a function of depth and temperature. The ratio is $\sim 0.1$ just below the Moho at $15 \mathrm{~km}$ depth and decreases linearly with depth to a value of $\sim 0.04$ down to $25 \mathrm{~km}$. Below this depth, the ratio remains constant at $\sim 0.04$ (Fig. $7 \mathrm{a}$ ) down to the $45 \mathrm{~km}$ depth. Figure $7 \mathrm{~b}$ shows the number of reflectors imaged along the profile in the mantle as a function of depth (temperature). We were able to identify 20 dipping reflectors just below the Moho; the number decreases to 7 at $30 \mathrm{~km}$ depth and then remains nearly constant at 5 down to $45 \mathrm{~km}$ depth (Table 1, Fig. 2b). Figure $7 \mathrm{c}$ shows the number of intra-plate oceanic earthquakes as a function of depth for a lithosphere of 50-60 Ma of age, both for local earthquakes in the Wharton Basin ${ }^{27,29}$ (Fig. 1, Table 2) and global events ${ }^{30}$. The depth of the global events are well constrained by waveform modelling ${ }^{30}$. For local events, we used re-located events until October 2007 (ref. 29) and the GCMT depth for the recent events $^{27}$. Although there could be uncertainties in the depth of these events, they provide a good indication of the pattern of seismicity with depth ${ }^{31}$. We also show the cumulative moment as a function of depth for the local events. These plots clearly indicate that the number of earthquakes linearly decreases down to $25 \mathrm{~km}$ and then remains constant below this depth down to $50 \mathrm{~km}$. The cumulative moment increases linearly with depth down to $25 \mathrm{~km}$, then decreases down to $35 \mathrm{~km}$, and then remains constant below this depth, following the pattern similar to the number of faults imaged (Fig. 7b). Interestingly, the $\mathrm{Mw}=7.2$ foreshock and $\mathrm{Mw}=8.62012$ main shock stand out, having exceptionally large moment, and initiating in the lower part of the lithosphere (Fig. 7c).

\section{Discussion}

The most important observation from our study is that there are a large number of dipping mantle reflectors imaged in the study area. There are two prominent reflections, DMR1 and DMR2, extending down to 45 and $37 \mathrm{~km}$ respectively and dipping in opposite directions. These reflections are rarely imaged going through the crust, although some of them do connect with faults imaged in the sediments. It is possible that the reflectors in the crust are steeply dipping, similar to the faults in the sediments

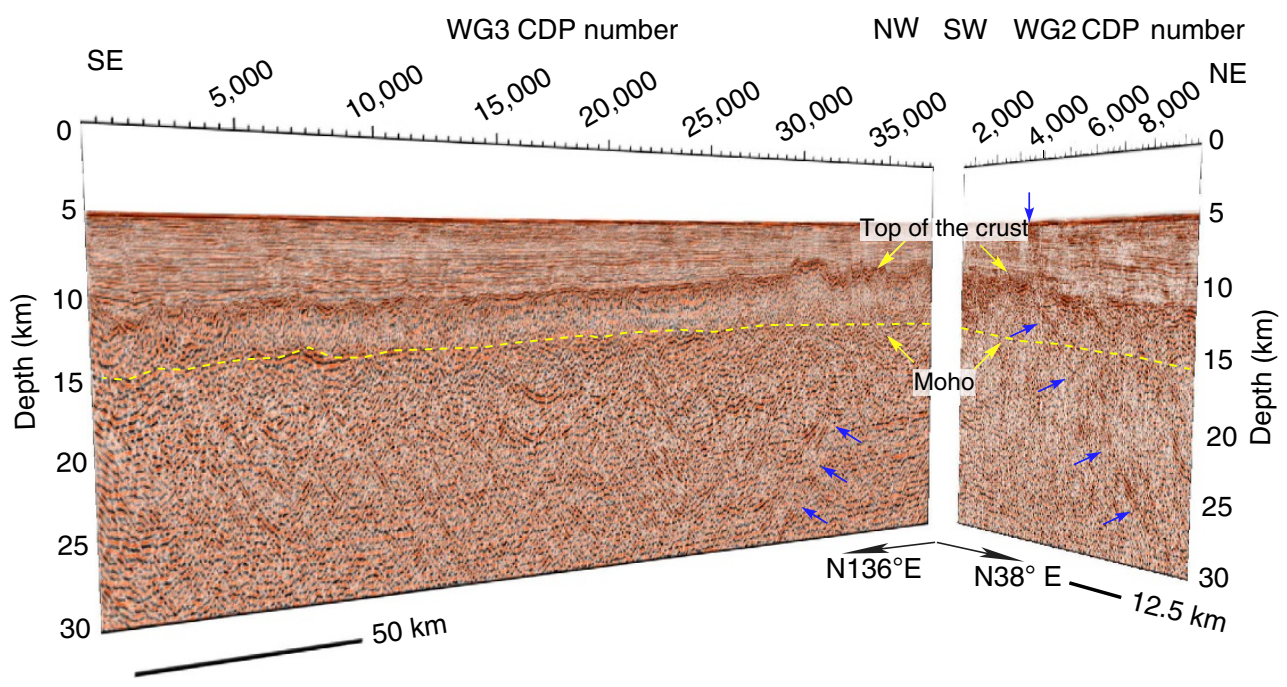

Figure 6 | 3D view of seismic images along profiles WG2 and WG3. The oceanic part of WG2 profile (right) and the whole WG3 profile (left) in the depth domain. Blue arrows mark dipping reflections. Both profiles cross fracture zone F6. A trench-ward dipping reflection can be followed from the seafloor down to $30 \mathrm{~km}$ depth. 
a

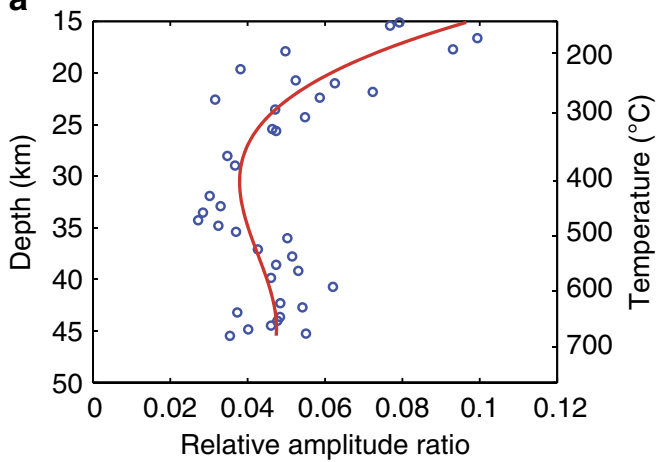

b

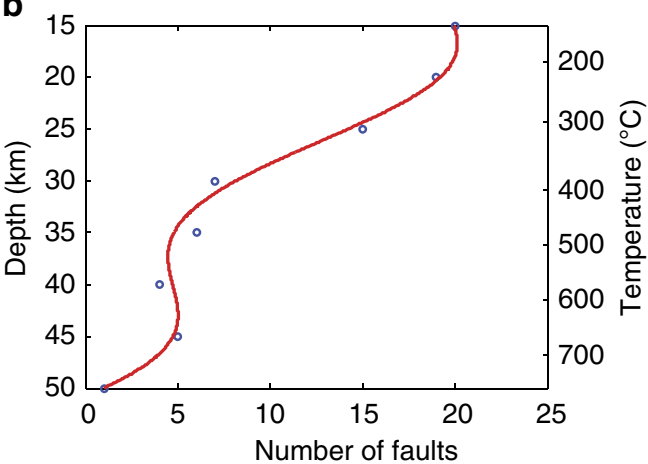

C

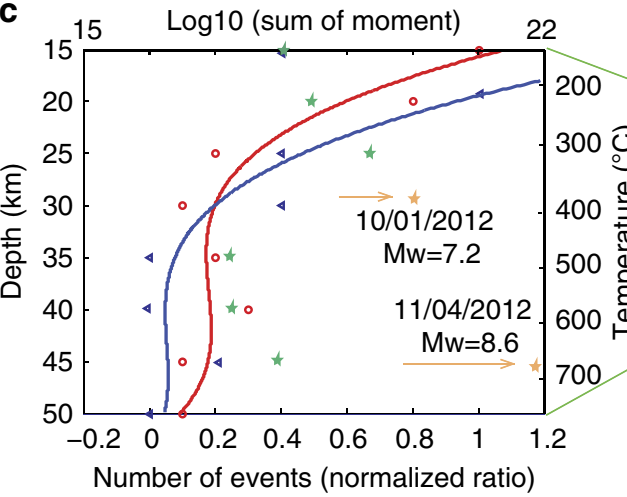

d

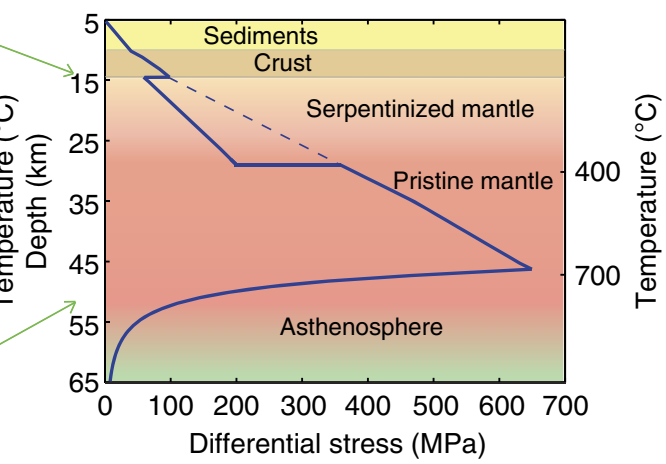

Figure 7 | Depth dependent parameters. (a) Relative amplitude ratio of the mantle reflector (DMR1) as a function of depth/temperature. The amplitude has been compensated for geometrical spreading and attenuation ( $Q p=1,000)$. The blue circles are the ratio of amplitudes (see Methods) and the red curve is a fitted curve using a 3rd order polynomial. (b) Number of faults observed along 233-km-long seismic profile WG3 in Fig. $2 b$ as a function of depth/temperature. The numbers of faults are estimated by drawing a horizontal line across the whole section at $5 \mathrm{~km}$ interval and counting the number of intersecting faults (Table 1). Blue circles represent the number of faults picked in a $5 \mathrm{~km}$ vertical bin. The red curve is a 4 th order polynomial fit. (c) The number of earthquakes and their cumulative moments as a function of depth/temperature for oceanic lithosphere of 50-60 Ma. Circles and red curve are local earthquakes shown in Fig. 1 while triangles and blue curves are global data and their fits ${ }^{30}$. Both data have been normalized separately and the number of events is in a $5 \mathrm{~km}$ depth bin. Green stars are the cumulative moments of the local earthquakes in Table 2 in the $5 \mathrm{~km}$ depth bin. The moments of the $M w=7.2$ and $M w=8.62012$ earthquakes (orange stars) stand out. (d) The approximate differential stress as a function of depth/temperature for a $60 \mathrm{Ma}$ lithosphere. Dash blue line represents the Byerlee law for a normal lithosphere of $60 \mathrm{Ma}$.

Table 1 | Number of Faults along profile WG3.

\begin{tabular}{cc|} 
Depth (km) & Number of faults \\
\hline 15 & 20 \\
20 & 19 \\
25 & 15 \\
30 & 7 \\
35 & 6 \\
40 & 4 \\
45 & 5 \\
50 & 1 \\
\hline
\end{tabular}

around F6, and therefore, it would be difficult to image them on a trench parallel profile. This is because a steeply dipping fault will offset sedimentary layers vertically, which is easy to identify, whereas a steeply fault in basaltic crust would have the same material on either side of the fault and hence would be difficult to image. The presence of a crustal fault penetrating down to $30 \mathrm{~km}$ along profile WG2 further supports this interpretation. This means that the deep mantle faults might be connected to faults observed in the sediments.

These reflections could be due to lithospheric faulting, magmatic or thermal cracking processes. The presence of frozen gabbroic melt in the mantle could produce appropriate impedance contrast to generate the observed reflections. The crust in the vicinity of profile WG3 was formed $\sim 56 \mathrm{Ma}$ ago in a fast spreading environment ${ }^{22}$, therefore the mantle must have been hot and the melt mobile, and hence it would have been difficult to retain melt in a steeply dipping narrow zone from the Moho down to $45 \mathrm{~km}$ depth; moreover, the maximum dip of imaged crustal magma chamber is $10-15^{\circ}$ (ref. 32).

On the other hand, the thermal stress in-between the fracture zones is strong enough to generate a deep cracking, which could fracture the lithosphere down to $\sim 20 \mathrm{~km}$ for a lithosphere of $50 \mathrm{Ma}$ (ref. 33). Since the most likely thermal crack system would have a cascade structure composed of widely spaced deep cracks and narrowly spaced shallow cracks ${ }^{33}$, whose dip would be nearly vertical -- much steeper than the mantle reflector imaged in our profile -- these reflectors could not be due to the thermal cracking, and consequently we suggest that these reflections were produced by faulting.

There were three strike-slip earthquakes in the WB in 2012, including the $\mathrm{Mw} 8.6$ great earthquake. The $\mathrm{Mw} 8.6$ event was $100 \mathrm{~km}$ south of profile WG3 and has a slip down to $\sim 45 \mathrm{~km}$ depth on the NNE-SSW trending plane around F6 extending up to profile WG3 (refs 12,34), and therefore, it is tempting to suggest that this earthquake might have re-activated the DMR2, which also seems to initiate below F6 and extends down to $37 \mathrm{~km}$ depth. However, the dip of DMR2 is too shallow $\left(30-40^{\circ}\right)$ as 
Table 2 | Earthquakes in the Wharton Basin.

\begin{tabular}{|c|c|c|c|c|c|c|}
\hline Date & Time & Latitude & Longitude & Depth (km) & Magnitude (Mw) & Type \\
\hline $1979 / 09 / 29$ & $18: 37$ & 1.11363 & 94.204887 & 24.0 & 6.8 & Strike-slip \\
\hline $1998 / 03 / 06$ & $0: 08$ & 1.658594 & 93.037704 & 13.1 & 5.5 & Strike-slip \\
\hline $2004 / 12 / 27$ & $18: 37$ & 3.324492 & 93.678909 & 19.0 & 5.4 & Normal \\
\hline $2005 / 01 / 08$ & $14: 59$ & 3.462692 & 92.704933 & 16.6 & 5.1 & Strike-slip \\
\hline 2005/01/19 & $16: 09$ & 3.521775 & 92.511208 & 14.1 & 5 & Strike-slip \\
\hline $2005 / 01 / 23$ & $20: 36$ & 2.757836 & 94.293365 & 15.5 & 5.2 & Strike-slip \\
\hline 2005/03/09 & $18: 27$ & 3.197151 & 93.455978 & 2.0 & 5 & Normal \\
\hline $2005 / 04 / 02$ & $22: 17$ & 2.456132 & 92.955391 & 17.5 & 5.3 & Strike-slip \\
\hline $2005 / 06 / 18$ & $8: 46$ & 3.668161 & 93.144798 & 17.3 & 4.9 & Strike-slip \\
\hline $2005 / 07 / 29$ & $20: 33$ & 2.843414 & 93.454292 & 13.7 & 5.5 & Normal \\
\hline $2006 / 04 / 19$ & $20: 36$ & 2.670439 & 93.18367 & 17.7 & 6.2 & Strike-slip \\
\hline $2007 / 10 / 04$ & $12: 40$ & 2.530956 & 92.850922 & 20.7 & 6.2 & Strike-slip \\
\hline $2010 / 01 / 22$ & $6: 46$ & 3.025 & 93.789 & 36.9 & 5 & Strike-slip \\
\hline 2012/01/10 & $18: 37$ & 2.396 & 93.175 & 29.0 & 7.2 & Strike-slip \\
\hline 2012/01/11 & $11: 56$ & 2.473 & 93.247 & 12.0 & 5 & Strike-slip \\
\hline $2012 / 01 / 27$ & $9: 54$ & 2.73 & 93.02 & 12.0 & 5.2 & Strike-slip \\
\hline 2012/04/11 & $8: 38$ & 2.327 & 93.063 & 46.0 & 8.6 & Strike-slip \\
\hline 2012/04/11 & $10: 43$ & 0.79 & 92.44 & 55.0 & 8.2 & Strike-slip \\
\hline $2012 / 04 / 12$ & 13:09 & 2.398 & 93.444 & 32.0 & 5.3 & Strike-slip \\
\hline $2012 / 04 / 12$ & $19: 26$ & 3.392 & 92.831 & 19.0 & 4.9 & Normal \\
\hline $2012 / 04 / 12$ & $20: 22$ & 3.753 & 92.746 & 12.0 & 5.4 & Strike-slip \\
\hline $2012 / 04 / 14$ & $15: 21$ & 0.275 & 92.133 & 12.0 & 5.4 & Thrust \\
\hline $2012 / 04 / 20$ & $23: 14$ & 2.153 & 93.347 & 41.0 & 5.9 & Thrust \\
\hline $2012 / 04 / 29$ & $3: 00$ & 1.911 & 93.73 & 37.0 & 5.3 & Strike-slip \\
\hline $2012 / 04 / 30$ & $21: 40$ & 3.322 & 92.967 & 12.0 & 5.1 & Strike-slip \\
\hline 2012/05/03 & $14: 41$ & 3.886 & 92.655 & 15.0 & 4.8 & Strike-slip \\
\hline 2012/05/06 & $8: 19$ & 3.96 & 92.6 & 12.0 & 4.9 & Strike-slip \\
\hline 2012/05/17 & $21: 58$ & 3.384 & 92.866 & 31.0 & 5.1 & Strike-slip \\
\hline $2012 / 08 / 20$ & $11: 18$ & 3.318 & 92.889 & 36.0 & 4.9 & Strike-slip \\
\hline $2012 / 10 / 11$ & $17: 07$ & 1.488 & 92.526 & 12.0 & 5.3 & Strike-slip \\
\hline
\end{tabular}

Earthquakes are in the area where the lithosphere is $\sim 56$ to 60 Ma old, from September 1979 to October 2012 . The data before October 2007 are relocated events using a double-difference method 29 . After 2007, earthquakes are from the GCMT catalogue 27 . The three recent earthquakes are marked in red.

compared to the dips of the 2012 WB earthquakes $\left(>70^{\circ}\right)$, suggesting that DMR2 could not have ruptured during the 2012 strike-slip earthquake. The second major fault DMR1, although extending deeper down to $45 \mathrm{~km}$, lies $105 \mathrm{~km}$ eastward of the Mw 8.6 event, also has smaller dip angle, hence could not have ruptured during the great earthquake either. Since the Mw 8.6 great strike-slip earthquake had a very complex fault orientation, it is possible these the faults imaged along our profile might have played some role in this complex faulting mechanism.

There are several mechanisms to generate these mantle faults. One possibility is that these faults are generated due to bendingrelated faulting in the outer rise region. In subduction zones, the incoming plate bends down towards the trench in response to compressive stresses induced at the plate interface, leading to varying degrees of shallow normal faulting and deeper thrust faulting in the outer rise region of the incoming plate ${ }^{35,36}$. Although bending related seismicity is termed as 'outer rise' earthquakes, most of the earthquakes occur in outer trench slope where the plate curvature is highest, which is generally about $50-75 \mathrm{~km}$ seaward off the trench axis ${ }^{37}$. Our profile WG3 lies within 32 and $66 \mathrm{~km}$ off the trench, hence in the zone of maximum curvature. Therefore, it is possible that the faults we imaged are related to plate bending. In the Middle American Trench, some of these bending related normal faults have been imaged down to $5-8 \mathrm{~km}$ below the Moho ${ }^{38}$. However, the plate bending tends to generate a double stress layer with in-plate tension in the upper layer and in-plate compression in the lower layer ${ }^{39}$, which could produce both a family of normal faults in the upper part and thrust faults in the deeper part with an aseismic zone separating the two types of faulting. The precise depth of the double-stress layer transition zone and its thickness vary depending upon the age of the subducting lithosphere, convergence rate and the dip of the subducting plate ${ }^{36}$. For the northern Sumatra suduction, the normal faulting should extend down to $20-25 \mathrm{~km}$ depth, followed by a $5-8 \mathrm{~km}$ thick different stress-state layers transition zone, and then thrust faulting should extend down to $50 \mathrm{~km}$ depth. However, the deepest reflector imaged on our profile extends from the Moho down to $45 \mathrm{~km}$ continuously, without any aseismic gap. Since the pole of plate rotation lies in the diffuse boundary, which includes our study area ${ }^{40}$, the intra-plate stress could get modified, affecting the resulting state of stress in the region and leading to the faulting pattern we observe along our profile.

There are only very few normal and thrust earthquakes, most of the earthquakes on the oceanic plate have dominantly strikeslip focal mechanisms (Fig. 1). The thrust events observed after the 2004 earthquake at the subduction front were attributed to a strong coupling between the subducting plate and the overriding plate up to the subduction front, and consequently the seaward propagation of the megathrust rupture up to the trench ${ }^{21,23}$. The bathymetry and seismic reflection data indicate that most of the dip-slip faults along F6 and F7 have N-S strike, not trench parallel as expected for bending related faulting. It is possible that the lateral variation in bending related stress due to the curvature at the trench resulting from the obliquity of the subduction, combined with dominant strike-slip deformation pattern in the $\mathrm{WB}$, leads to the complex faulting pattern observed in the region.

Besides the plate bending effect in the outer rise, another possibility is that these faults were formed by the reactivation of ridge-parallel normal faults as thrust faults a long time ago and 
they are inactive now ${ }^{27}$. In the CIB, extensive thrust faults have been imaged cutting through the crust, some of them extending into the mantle $\mathrm{e}^{41,42}$, which are suggested to be due to the active intra-plate deformation in the CIB. There too, not all the mantle faults extend into the crust and subsequently to the sediments, indicating that these faults are either older or associated with the original oceanic fabric. The timing of the faulting would be difficult to estimate, but they must have been formed after several tens of million years from the time of the formation of the oceanic crust for the brittle lithosphere to be thick enough $(40-50 \mathrm{~km})$ and to lie below $750{ }^{\circ} \mathrm{C}$ (ref. 43). The main tectonic events effecting this lithosphere were the collision of India with Australia at $\sim 40 \mathrm{Ma}$, and the initiation of the deformation in the Central Indian Basin $\sim 15 \mathrm{Ma}$ ago $^{6}$ with enhanced deformation at $8 \mathrm{Ma}^{7}$, hence these faults might have been formed during any of these two events.

On the other hand, some studies found that the $\mathrm{Mw}=8.6$ event also ruptured NWN-SES faults ${ }^{12,18}$, which are unrelated to the oceanic fabric. On the contrary, a recent bathymetric and seismic study indicates the absence of any such WNW-ESEtrending faults ${ }^{44}$. This study also indicates the presence a complex set of Riedel faults with NNE and SSE orientation.

It is difficult to distinguish the different origins of these mantle reflections, but the bending related stresses combined with the stresses caused by diffuse deformation in the WB are the most likely cause of these faulting. However, their depth dependent properties provide important insight about the nature of the deformation as a function of depth. The linear decrease in the amplitude ratio of the reflectors with depth cannot be attributed to a temperature-related intrinsic attenuation, because if it were the case, the reflection coefficient should continue to decrease with depth below $25 \mathrm{~km}$. The frequency versus depth plot (Supplementary Fig. 7) indicates that the dominant frequency of DMR1 decreases from 10 to $7 \mathrm{~Hz}$, and hence the effect of the intrinsic attenuation should be small. Assuming a thermal profile for a $\sim 60 \mathrm{Ma}$ old oceanic lithosphere (see Methods), the mantle temperature should be $\sim 150^{\circ} \mathrm{C}$ below the Moho increasing to $680^{\circ} \mathrm{C}$ at $45 \mathrm{~km}$ depth, and hence the attenuation should increase with depth, instead of decreasing, which indicates that the amplitude ratio represents the change in the reflection coefficient (see Methods). The negative polarity of the dipping reflection (Fig. 4) suggests that it should be due to the presence of a thin low velocity zone associated with a fault. The water penetrating along the damaged fault zone, produced by any of the processes discussed above, could serpentinize the mantle peridotite and produce a low velocity reflective zone relative to the surrounding unaltered lithosphere. The serpentinization has also been invoked to explain high heat flow and sub-Moho reflections in the $\mathrm{CIB}^{42}$. We used the amplitude ratio to estimate the reflection coefficient of the fault (see Methods), which will depend on its overall degree of serpentinization. A linear decrease in the degree of serpentinization, suggested by the variation in the reflection coefficient between the Moho and the $\sim 25 \mathrm{~km}$ depth, may be expected if the pressure promotes the closure of cracks and a reduction of permeability with depth that inhibits fluid circulation and therefore serpentinization.

The change in the reflection coefficient at $\sim 25 \mathrm{~km}$ depth is associated with a lithospheric temperature of $300-350{ }^{\circ} \mathrm{C}$, which is close to the upper limit of the stability of lizardite serpentinite ${ }^{45}$. The temperature at $45 \mathrm{~km}$ depth would be $\sim 680^{\circ} \mathrm{C}$, which is much higher than the stability limit of serpentine at $\sim 400^{\circ} \mathrm{C}$ (ref. 46 ). It is interesting to note that the change in the above properties coincides with the aseismic zone at $25-30 \mathrm{~km}$ depth that would separate the regions of outer rise bending-related normal faulting from deeper thrust faulting, and would likely inhibit the penetration of fluids into the deeper parts of the mantle ${ }^{31}$. So below $25 \mathrm{~km}$ depth, the reflections display a lower velocity contrast that may be due to the presence of other alteration phases, such as antigorite serpentinite that is stable at higher temperature (up to $600-650^{\circ} \mathrm{C}$ ) (ref. 47) or some other processes, such as shear zones.

Mylonite shear zones are formed due to the deformation along a fault zone at higher temperatures. The critical temperature over which the ductile deformation predominates is estimated to be $620( \pm 120){ }^{\circ} \mathrm{C}$ for olivine ${ }^{48}$. The brittle-ductile interface would be reached at a depth of $38 \pm 8 \mathrm{~km}$ for a $60 \mathrm{Ma}$ old oceanic lithosphere $^{49}$. Some peridotite shear zones reach extremely high temperature $\left(600-800^{\circ} \mathrm{C}\right)$, sufficient to form veins of melt that rapidly cool and are chilled to glass ${ }^{50,51}$. So at such great depths as DMR1 with high pressure, high temperature and high slip (large magnitude and stress drop caused by great earthquakes, such as the 2004 Sumatra earthquake), the lithospheric failure zone may melt and produce shear zones.

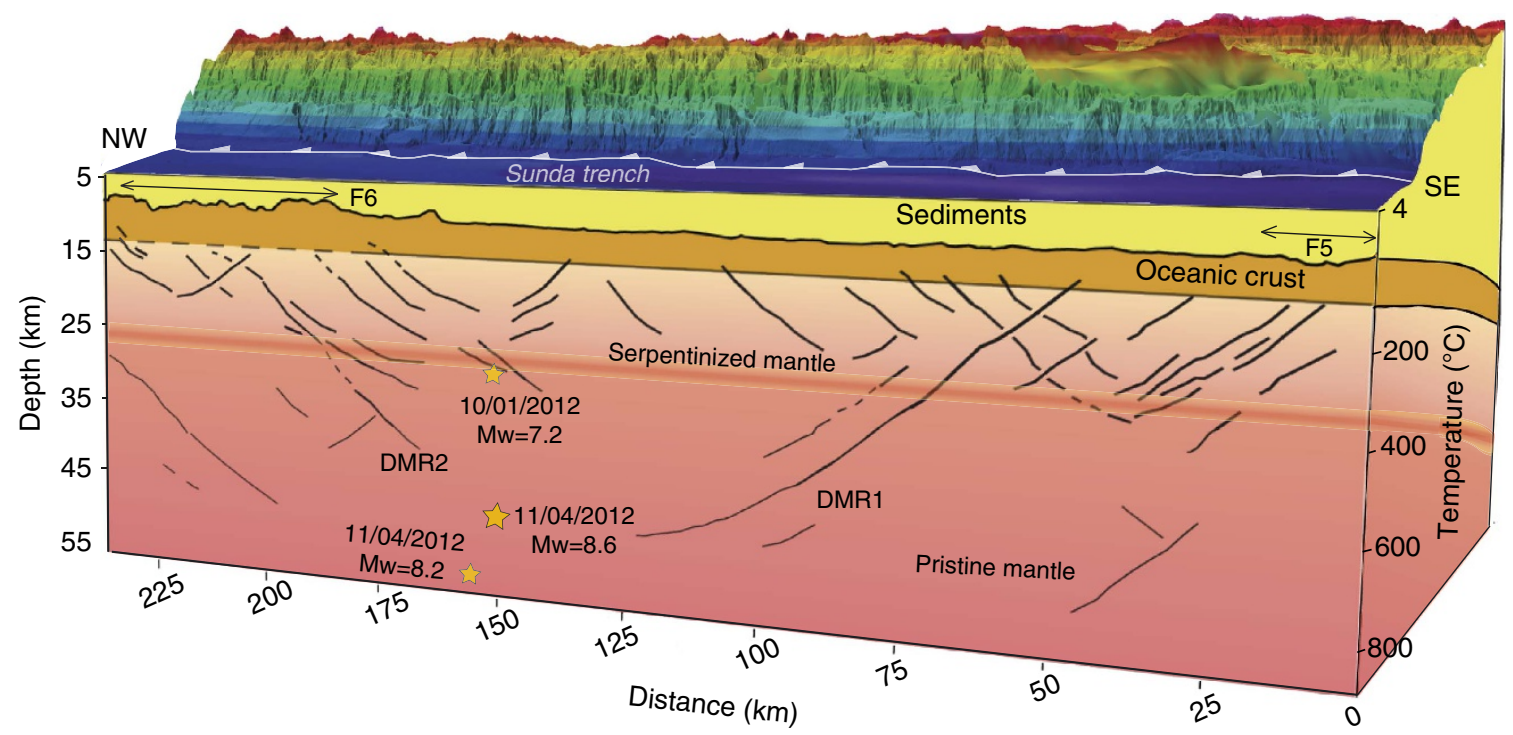

Figure 8 | Schematic diagram. A 3D block diagram showing the interpreted faults imaged on profile WG3, location of the fracture zones F5 and F6, and projected hypocentres of January and April 2012 earthquakes. The Sunda trench and accretionary prism are also shown in the background. 
The presence of a large number of faults just below the Moho in both WG3 and WG2 (Figs 2, 6 and 7b) extending down to a depth of $\sim 25 \mathrm{~km}$ suggests that the upper mantle is extremely fractured. The observation of a large number of earthquakes just below the Moho also supports the idea of a highly fractured upper mantle. The decrease in both the number of faults and the number of earthquakes with depth suggests that deformation decreases with depth down to $25-30 \mathrm{~km}$, which might be associated with the decrease in serpentinization with the increase of temperature.

Below 25-30 km, both the number of faults and the number of earthquakes remain constant down to $50 \mathrm{~km}$ depth, suggesting a change in the regime of the lithospheric deformation, possibly affected by and also controlling the rheology of the mantle. Figure $7 \mathrm{~d}$ shows a schematic diagram demonstrating the rheology as a function of depth (temperature). Sediments and the crust follow the Byerlee law rheology ${ }^{43}$. Just below the Moho, the presence of only $\sim 10-15 \%$ of lizardite serpentinization can reduce the strength of the lithosphere significantly ${ }^{52}$, and particularly that of serpentinite-bearing faults, owing to its low coefficient of friction relative to the Byerlee law $(\mu \sim 0.3-0.4$ versus $\mu \sim 0.85$ ). At a depth of $25-30 \mathrm{~km}$, at the stability limit of lizardite serpentinite, the strength of the lithosphere should increase due to the change in friction according to the Byerlee law $(\mu \sim 0.85)$. In this case, the result is a strength envelope with a 'very weak upper mantle' between the Moho and $\sim 25 \mathrm{~km}$ depth and a strong lower mantle down to the base of the lithosphere. This strength envelope is consistent with the seismic moment as a function of depth during the 2012 Wharton Basin earthquakes ${ }^{12}$.

Our results suggest that the deformation in the Wharton Basin oceanic lithosphere can be divided into two layers: (i) serpentinized upper lithosphere (SL) from the Moho down to $25-30 \mathrm{~km}$ and (ii) a pristine lithospheric mantle (PL) from $25 \mathrm{~km}$ down to the base of the lithosphere at $60 \mathrm{~km}$ depth (Fig. 8). The finite fault model of the 2012 great Wharton Basin earthquakes also shows two zones of maximum slip, $5-25 \mathrm{~km}$ and $30-50 \mathrm{~km}$ (ref. 12), supporting our idea of a two-layer model of the lithospheric mantle deformation. Numerical modelling studies suggest that the large earthquakes initiate in a large stress-drop regime at greater depth whereas small earthquakes initiate at shallow depth ${ }^{52}$, confirmed by the 2012 earthquakes, supporting our observation.

Most of the normal earthquakes in the outer arc rise occur in the SL whereas the thrust events initiate below $25 \mathrm{~km}$ depth down to $40 \mathrm{~km}$ depth $^{30}$ in the PL; the deep lithospheric faults imaged here may act as weak zones that may be reactivated as thrust faults. Highly fractured SL should be able to transport a large amount of water in the Benioff zone as suggested by other seismological studies ${ }^{53,54}$. The dehydration of serpentinite at the SL/PL boundary may create a reaction zone leading to seismicity and would be helpful to explain the location of the second (lower) Benioff zone observed here in the double Benioff zones (DBZ) $)^{55,56}$. The thickness of SL/PL will depend on the age of the lithosphere. The subducting slab in our study area contains a $\sim 15-17 \mathrm{~km}$ thick SL (Fig. 7), which corresponds to the estimated separation of the Benioff zone for a $56 \mathrm{Ma}$ old lithosphere ${ }^{56}$, and is in an agreement with the observed results offshore Sumatra ${ }^{56}$. We projected earthquake events ${ }^{57}$ along a cross section perpendicular to the subduction around WG3 (Fig. 9a) to obtain a vertical profile of all the events (Fig. 9b), which shows a separation depth of DBZ at $12 \sim 18 \mathrm{~km}$ below the top of the crust (Fig. 9c), consistent with the theoretical prediction. A vertical aseismic zone with a thickness of $5 \sim 7 \mathrm{~km}$ separating shallow normal-faulting earthquakes and deeper thrust-faulting earthquakes is also consistent with the doublestress layer paralleling to the Benioff zone in the Sumatra subducting plate ${ }^{57}$. Therefore, the SL/PL boundary observed in our seismic image corresponds to a rheological and alteration boundary that could indeed be the locus of seismicity corresponding to the second Benioff zone.

Although our two-layer deformation model explains all the existing seismic and seismological observations, more ultra-deep seismic reflection data from another part of the WB and the CIB are required to quantify the lateral extent of the mantle deformation in the Indian Ocean. Imaging of the crustal faults is also extremely important because of the links between the deep reflectors and the crustal faults are of fundamental importance. The study should be further extended to other outer rise areas using ultra-long streamers to characterise the deformation between shallow normal faulting and deep thrust faulting.

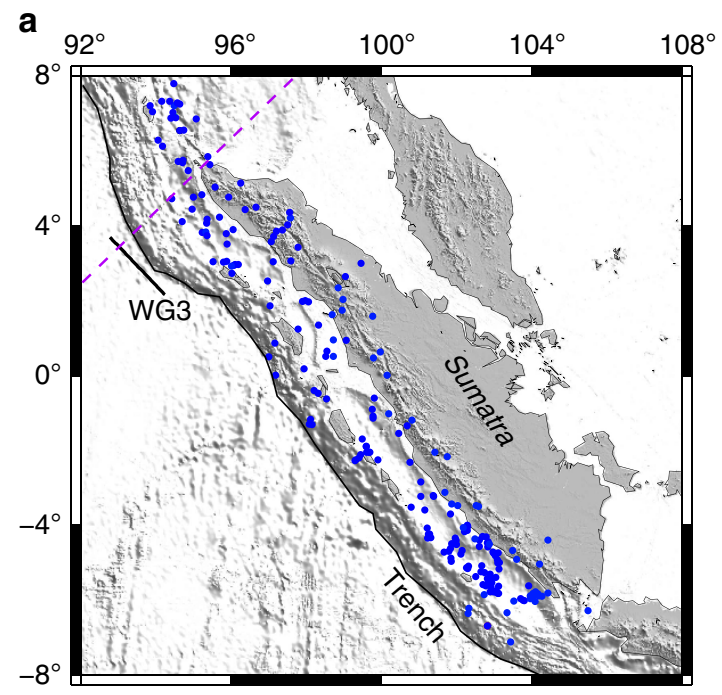

b
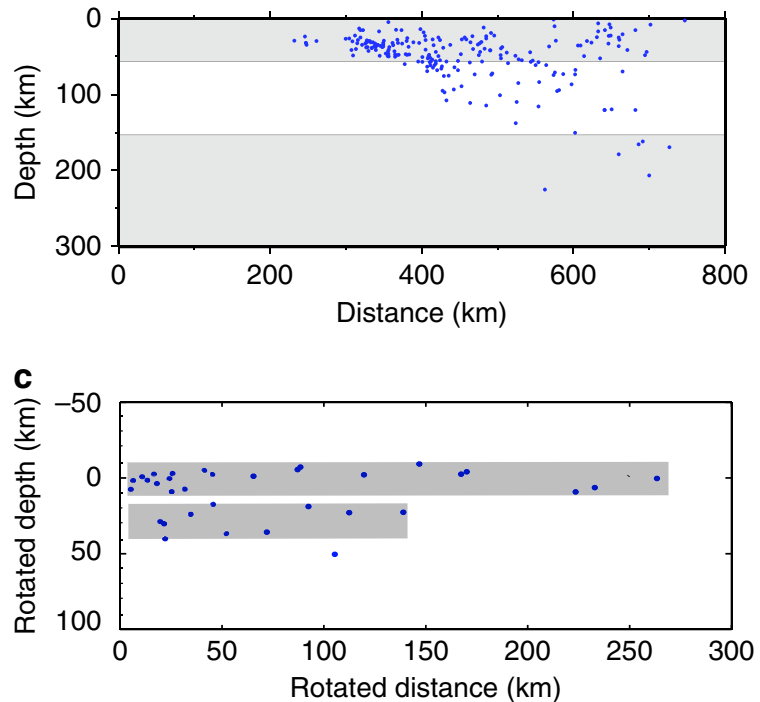

Figure 9 | Double Benioff Zone. (a) The earthquakes in Sumatra area ${ }^{57}$. (b) Projected events along a cross section marked by the dashed line in a which is perpendicular to WG3. The events in the middle white window are used in c. (c) The events versus depth plot showing the Double Benioff Zone. The earthquakes shown in white window in $\mathbf{b}$ were projected at the slab-normal locations and were rotated along the plate interface. 


\section{Methods}

Seismic data acquisition. The 233-km-long offset deep seismic reflection profile WG3 was acquired by the WesternGeco marine seismic vessel Geco Searcher in July 2006. The profile was shot in a NW-SE direction, nearly parallel to the trench at $32-66 \mathrm{~km}$ distance. It covers the entire segment of the oceanic crust, bounded by two fracture zones, F5 and F6 that lie at the southeast and northwest ends of the profile, respectively. WG2 was shot traversing the subduction zone orthogonally with a direction of $\mathrm{N} 38^{\circ} \mathrm{E}$ crossing the whole subduction system ${ }^{21,58}$. Here we only show the oceanic part of the profile (Fig. 1). To enhance low frequency signals, the seismic data were acquired using a 12-km-long streamer towed at $15 \mathrm{~m}$ depth. The seismic source was composed of 6 sub-arrays with 8 airguns in each sub-array making a total array volume of 10170 in ref. 3, with an operating pressure of 2,000 p.s.i. The seismic source was towed at a depth of $15 \mathrm{~m}$ and the shot interval was $50 \mathrm{~m}$. The individual hydrophone spacing in the Q-Marine streamer was $3.125 \mathrm{~m}$. After applying digital noise attenuation and appropriate digital spatial anti-alias filters ${ }^{59}$, the digital signals were spatially resampled to 958 channels with a digital hydrophone group interval of $12.5 \mathrm{~m}$. The seismic data record length was $20.48 \mathrm{~s}$ with a temporal sample interval of $2 \mathrm{~ms}$. The data were rich in low frequency signal and were very helpful in imaging the deeper structure such as the deep crust and uppermost mantle.

Low frequency enhancement. In order to image deep structures, one requires low frequency seismic energy as low frequency signals penetrate deeper in the earth due to low attenuation. High frequency energy gets attenuated rapidly with depth. As discussed above, both the airgun source and the streamer were deployed at $15 \mathrm{~m}$ water depth. Since the sea surface acts like a mirror, with a reflection coefficient of -1 , it reflects both the seismic source energy at its generation (Supplementary Fig. 9b) and the up propagating seismic wavelet at the receivers (Supplementary Fig. 9c) during recording, and produces almost perfect reflections as well as a phase change as shown in Supplementary Fig. 9e; these are called ghosts (Supplementary Fig. 9). The small travel time difference between the primary and ghosts could introduce notches into the spectra of the seismic data, reducing the bandwidth of the signal (Supplementary Fig. 9f). The effect of ghost in reducing the low frequency energy plays an important role in imaging very deep structures.

Since we know the depth of the streamer and source, and assuming a P-wave velocity of $1500 \mathrm{~m} \mathrm{~s}^{-1}$ in the water, we can predict the arrival time difference of ghost reflection, which will be $0.02 \mathrm{~s}$ for the normal incidence. Then we can generate a ghosted signal response of $+1,-2,+1$ containing both source and receiver ghosts (Supplementary Fig. 9e). Corresponding to this ghosted response, the first ghost notch occurs at $50 \mathrm{~Hz}$ in the frequency domain. With this information, we can design an inverse filter and remove the effect of the ghosts. From the convolution theory, we calculate the reciprocals of the ghost signal spectrum as an inverse filter. To make it a band limited minimum phase filter, we added a stability factor to the amplitude spectrum, which avoids the minus infinity caused by the alternative Hilbert transform approach and inaccurate signal ${ }^{60}$.

By using the synthetic ghosts as input (Supplementary Fig. 9e), we filter it with our inverse filter, and obtain a deghosted signal (Supplementary Fig. 9g). The amplitude spectrum of input and output (Supplementary Fig. 9h) are shown in the units of $\mathrm{dB}$, which indicate that the signal between 0 and $25 \mathrm{~Hz}$ has been amplified after the application of the deterministic inverse ghost filter. Similarly, useful amplification is achieved between $25-40 \mathrm{~Hz}$. The deterministic inverse ghost filter is followed by the application of a low pass filter with a cut off at $50 \mathrm{~Hz}$. When we apply this technique to the real data from WG3 and compare our results to the results processed by WesternGeco ${ }^{27}$, our method achieve better performance both in the shallow and the deep parts of the section (Supplementary Fig. 10).

Data processing. In order to enhance low frequencies and to preserve high frequencies, the pre-stack processing was done in shot, common depth-point (CDP) as well as common receiver domains. The main steps in the shot domain include the removal of the instrument noise caused by the recording instrument anti-alias filter, low frequency enhancement using the deterministic inverse ghost filter, swell noise attenuation and short period multiple attenuation with predictive deconvolution to remove the interlayer multiples.

Since the seismic source was powerful, the multiples are very strong and quite challenging to remove. Considering the seafloor reflections arrive at $\sim 6 \mathrm{~s}$ two-waytravel time (TWTT), the first multiples will arrive at $\sim 12 \mathrm{~s}$. Furthermore, the raw shot record also contains strong residual shot noise from the previous shot, therefore we used a Radon filter applied to the CDP gathers after parabolic Radon transformation and followed by a tau-p filter after slant-stack transformation in the common receiver gather domain. To preserve primary amplitudes, the demultiple strategy must be oriented to the utilization of the strengths of each methods by combining different methods. The amplitude versus offset analysis is an important tool in demultiple processing. For example, when there is sufficient move-out differential between primaries and multiples, a properly designed Radon demultiple can lead to an effective removal of multiples while preserving primary reflection amplitudes well at the far offsets. So through optimal parameterization, we mute the near offset data in the CDP domain then stack; in this way the primary reflections are preserved with weak residual multiples. Scattering noise reduction was done prior to doing velocity analysis. The last two steps of the processing sequence were CDP stacking and the application of a 2-D time-space post-stack Kirchhoff migration. As shown in Supplementary Fig. 1, the multiples have been attenuated very well. However, there are some weak flat reflections between $12-16 \mathrm{~s}$, which we interpret as residual multiples. To reduce the uncertainties in the depth conversion, our interval velocity for depth conversion was produced by combining two models from two sources: the part above the Moho came from tomographic inversion results ${ }^{23}$, and the deep part beneath the Moho came from the study of the NoMelt experiment ${ }^{24}$.

Relative amplitude calculation. Calculating the absolute reflector amplitude of a deep mantle reflector is difficult because the true amplitude gets modified during the data processing. One way to estimate the relative amplitude is to find a shallower continuous reflector that has a good impedance contrast from an interface as a reference reflector and then compute the relative amplitude for the target reflector. Since the Moho reflector here above DMR1 is complex and its amplitude varies along the profile, we decided to use the seafloor amplitude as the reference interface, which is more or less constant along the whole profile. We firstly used a moving window along the DMR1 and DMR2 in the migration image and detected the maximum amplitudes at different depths. We then applied geometric spreading compensation and corrected for the loss of amplitude due to the attenuation as a function of depth. The amplitude ratios for DMR1and DMR2 are shown in Fig. 7a and Supplementary Fig. 8.

Reflection coefficient estimation. Normally, we use the seafloor reflection coefficient to estimate the relative reflection coefficient of deep events. Since there are thick sediments, one must take reflection coefficients at each sediment interface into account up to the deep reflector. Since we did not have any constrains on the sediment reflectivity, we used the Moho reflection coefficient as a reference as there were not many reflections between the Moho and the mantle reflectors. We assumed a $\mathrm{P}$ wave velocity of $6.8 \mathrm{~km} \mathrm{~s}^{-1}$ and $7.5-8.0 \mathrm{~km} \mathrm{~s}^{-1}$, and the densities to be $2.9 \mathrm{~g} \mathrm{~cm}^{-3}$ and $3.0-3.1 \mathrm{~g} \mathrm{~cm}^{-3}$, above and below the Moho, respectively. Considering the incidence angle at this depth $(\sim 15 \mathrm{~km})$ is close to zero because of the acquisition geometry, we estimated the reflection coefficient as

$$
R=\frac{\rho_{2} v_{2}-\rho_{1} v_{1}}{\rho_{2} v_{2}+\rho_{1} v_{1}}
$$

which gives a Moho reflection coefficient between 0.066 and 0.114

Before calculating the relative amplitude for DMR1 to the Moho, the amplitude of DMR1 should be compensated for relative geometric spreading and Q attenuation, similar to the relative amplitude. The geometric spreading is proportional to the distance, and the material intrinsic attenuation effects can be corrected based on

$$
A=A_{0} e^{\left(-\frac{\pi f t}{Q}\right)}
$$

where $A_{0}$ is the original amplitude before attenuation, $A$ is the observed amplitude, $f$ is the frequency of the seismic wave, $t$ is the travel time in the medium. Here we assigned $Q=1,000$ in the mantle for $\mathrm{P}$ wave. After correction, we obtained a relative amplitude of $\sim 0.0269$ at $16 \mathrm{~km}$ depth and $\sim 0.018$ at $45 \mathrm{~km}$ for DMR1. The amplitude of the Moho is $\sim 0.09$, therefore the reflection coefficient values for DMR1 at $16 \mathrm{~km}$ would between 0.021 and 0.039 , and that at $45 \mathrm{~km}$ would be 0.014 and 0.026 . These results are consistent with the $\mathrm{P}$ wave reflection coefficients that were found for a mantle fault zone in a previous study ${ }^{61}$.

Temperature. In order to relate our results with the rheology of the lithosphere, we estimated the temperature using the half-space plate-cooling model ${ }^{62}$ :

$$
T(x, z)=T_{\mathrm{m}}\left[\frac{z}{a}+\sum_{n=1}^{x} c_{n} e^{\left(-\frac{\beta_{n} x}{a}\right)} \sin \left(\frac{n \pi z}{a}\right)\right],
$$

where $x$ is the distance from the ridge and $z$ is the depth below the seafloor, $a$ is the asymptotic thermal plate thickness, $T_{\mathrm{m}}$ is the basal temperature, and

$$
c_{n}=\frac{2}{n \pi}, \beta_{n}=\left(R^{2}+n^{2} \pi^{2}\right)^{\frac{1}{2}}-R, R=\frac{v a}{2 \kappa} .
$$

$R$ is the Peclet number relating the advective and conductive heat transfer, $v$ is the half spreading rate, and $\kappa=k /\left(\rho_{\mathrm{m}} \mathrm{C}_{\mathrm{p}}\right)$ is the thermal diffusivity where $k$ is the thermal conductivity, $\rho_{\mathrm{m}}$ is the mantle density and $C_{\mathrm{p}}$ is the specific heat. This model is consistent with the model proposed by McKenzie et al. ${ }^{30}$

We have used the following parameters ${ }^{30,62}$ : a plate thickness of $125 \mathrm{~km}$ with a basal temperature of $1,350^{\circ} \mathrm{C}$, a coefficient of thermal expansion of $3.28 \times 10^{-5} \mathrm{~K}^{-1}$, a specific heat of $1.2 \mathrm{~kJ} \mathrm{~kg}^{-1} \mathrm{~K}^{-1}$, a mantle density of $3.4 \mathrm{~g} \mathrm{~cm}^{-3}$, and a thermal conductivity of $3.14 \mathrm{~W} \mathrm{~m}^{-1} \mathrm{~K}^{-1}$. We calculated a $2 \mathrm{D}$ temperature profile as a function of age and depth. Since the age of the lithosphere along our profile is $55-58 \mathrm{Ma}$, we plotted one-dimensional temperature along with depth in Figs 7 and 8.

Differential stress estimation. The age of the lithosphere in our study area is about $55-60 \mathrm{Ma}$ and the oceanic lithosphere thickness is $\sim 60 \mathrm{~km}$. Though there is no direct way to estimate the strength of the lithosphere, the Byerlee law ${ }^{63}$ 
describes the depth of transition from a brittle, frictional rheology to a temperature-dependent power-law rheology, which can provide some idea of the brittle-plastic transition. For dry olivine, we used the following equation ${ }^{64}$

$$
\dot{\varepsilon}=A \sigma^{n} e^{-Q / R T}
$$

where $\dot{\varepsilon}$ is the strain rate, $A$ is a pre-exponential factor, $\sigma$ is the differential stress, $n$ is the stress exponent, $Q$ is the apparent activation energy, $R$ is a constant and $T$ is the absolute temperature. The following parameters were used for dry olivine: $A=2.4 \times 10^{5} \mathrm{~s}^{-1} \mathrm{MPa}^{-1}, Q=540 \mathrm{~kJ} \mathrm{~mol}^{-1}, n=3.5, R=8.3144 \times 10^{-3}$ (refs 46,65 ). The geotherm for this area is based on the results from the above temperature calculation. The strain rate is $10^{-15} \mathrm{~s}^{-1}$, the friction coefficient is 0.85 for the Byerlee law. According to a previous study ${ }^{54}$, once the degree of serpentinization reaches $\sim 13 \%$, its effects on rheology will be similar to the rheology of a pure serpentine. Based on the above serpentinization estimation, we have used the lizardite serpentine friction law ${ }^{65}$ for the upper $15-25 \mathrm{~km}$, assuming a friction coefficient of 0.3 (ref. 46, Fig. 7d).

Dip angle of the faults. According to the geometrical relationship between the direction of the profile and a true dip along a profile, we can use their dihedral angle and the apparent dip of the two deepest faults to investigate the possible true oblique dip. Since the velocity model estimated from the seismic data dip move-out is not accurate, especially for deep structures, due to the limited offset range of the data, we constructed a time-to-depth conversion velocity model that is made up of two parts. The velocity model for the shallow section above the Moho is derived from travel time tomography. In the mantle, besides Lizarralde et al. velocity model ${ }^{24}$, we also used two other constant velocity models as extreme members for the dip calculation: $7.5 \mathrm{~km} \mathrm{~s}^{-1}$ and $8.9 \mathrm{~km} \mathrm{~s}^{-1}$, respectively. We estimated the dip by projecting these reflectors in different plausible directions of faults (Supplementary Figs 5 and 6). Here we defined the apparent dip as an angle between the horizontal and the tangent line of the dipping mantle reflectors at different depths. The dominant apparent dip of DMR1 on this profile decreases with increasing depth from $40^{\circ}$ below the Moho to $12^{\circ}$ at $\sim 45 \mathrm{~km}$ depth based on the Lizarralde et al. velocity model (ref. 24 , Supplementary Fig. 5a) and with a $\pm 4^{\circ}$ variation (Supplementary Fig. 5b,c). As shown in Supplementary Fig. 5, the projections onto the F5 plane (light blue) have the steepest dip. The dip angles decrease from $50^{\circ}$ to $20^{\circ}$ with increasing depth when the mantle velocity is $8.9 \mathrm{~km} \mathrm{~s}^{-1}$ (Supplementary Fig. 5b); while they decrease from $45^{\circ}$ to $18^{\circ}$ for a mantle velocity of $7.5 \mathrm{~km} \mathrm{~s}^{-1}$ (Supplementary Fig. 5b,c). The depth difference of the DMR1 between the lowest and highest velocity is almost $6 \mathrm{~km}$ (Supplementary Fig. 5b,c)

The similar projections for DMR2 are shown in Supplementary Fig. 6. The DMR2 is steeper than the DMR1 and the dip angle does not change too much with increasing depth. Using the Lizarralde et al. velocity model (ref. 24, Supplementary Fig. 6a), the apparent dip of the DMR2 (dark blue) decreases from $30^{\circ}$ to $25^{\circ}$ from top to bottom, the steepest dip projection is on F6 plane, decreases from $41^{\circ}$ to $34^{\circ}$. When we change the velocity model to be a constant mantle velocity of $8.9 \mathrm{~km} \mathrm{~s}^{-1}$ (Supplementary Fig. 6b), the apparent dip of the fault decreases from $35^{\circ}$ to $28^{\circ}$ from top to bottom, the steepest dip projection on F6 plane decreases from $44^{\circ}$ to $36^{\circ}$. The apparent dip of the fault decreases from $28^{\circ}$ to $24^{\circ}$ when the mantle velocity is $7.5 \mathrm{~km} \mathrm{~s}^{-1}$ (Supplementary Fig. 6c), the steepest dip projection on F6 plane decreases from $40^{\circ}$ to $33^{\circ}$

\section{References}

1. Weissel, J. K., Anderson, R. N. \& Geller, C. A. Deformation of the IndoAustralian Plate. Nature 287, 284-291 (1980).

2. Wiens, D. A. et al. A diffuse plate boundary model of Indian Ocean tectonics. Geophys. Res. Lett. 12, 429-432 (1985).

3. Bull, J. M. \& Scrutton, R. A. Fault reactivation in the central Indian Ocean and the rheology of oceanic lithosphere. Nature 344, 855-858 (1990).

4. Royer, J.-Y. \& Gordon, R. G. The motion and boundary between the Capricorn and Australian plates. Science 227, 1268-1274 (1997).

5. Deplus, C. et al. Direct evidence of active deformation in the eastern Indian oceanic plate. Geology 26, 131-134 (1998).

6. Krishna, K. S., Bull, J. M. \& Scrutton, R. A. Early (pre-8 Ma) fault activity and temporal strain accumulation in the central Indian Ocean. Geology 37, 227-230 (2009).

7. Gordon, R. G., DeMets, C. \& Royer, J.-Y. Evidence for long-term diffuse deformation of the lithosphere of the equatorial Indian Ocean. Nature 395, 370-374 (1998).

8. Delescluse, M. \& Chamot-Rooke, N. Instantaneous deformation and kinematics of the India-Australia plate. Geophys. J. Int. 168, 818-842 (2007).

9. Cloetingh, S. \& Wortel, R. Stress in the Indo-Australian plate. Tectonophysics 132, 49-67 (1986)

10. Abercrombie, R. E., Antolik, M. \& Ekström, G. The June 2000 Mw 7.9 earthquakes south of Sumatra: Deformation in the India-Australia plate. J. Geophys. Res. 108, B2018 (2003).

11. Engdahl, E. R., Villaseñor, A., DeShon, H. R. \& Thurber, C. H. Teleseismic relocation and assessment of seismicity (1918-2005) in the region of the 2004 Mw 9.0 Sumatra-Andaman and the $2005 \mathrm{Mw} 8.6$ Nias Island Great earthquakes. Bull. Seism. Soc. Am. 97, S1-S19 (2007).
12. Wei, S., Helmberger, D. \& Avouac, J.-P. Modeling the 2012 Wharton Basin earthquake off Sumatra; Complete lithospheric failure. J. Geophys. Res. 118, 3592-3609 (2013).

13. Fullerton, L. G., Sager, W. W. \& Handschumacher, D. W. Late Jurassic-early Cretaceous evolution of the eastern Indian Ocean adjacent to northwest Australia. J. Geophys. Res. 94, 2937-2953 (1989).

14. Liu, C. S., Curray, J. R. \& McDonald, J. M. New constraints on the tectonic evolution of the eastern Indian Ocean. Earth Planet. Sci. Lett. 65, 331-342 (1983).

15. Prawirodirdjo, L. et al. One century of tectonic deformation along the Sumatran fault from triangulation and GPS surveys. J. Geophys. Res. 105, 28343-28361 (2000).

16. Deplus, C. Indian Ocean actively deforms. Science 292, 1850-1851 (2001).

17. Robinson, D. P., Henry, C., Das, S. \& Woodhouse, J. H. Simultaneous rupture along two conjugate planes of the Wharton Basin earthquake. Science 292, 1145-1148 (2001).

18. Meng, L. et al. Earthquake in a maze: Compressional rupture branching during the $2012 \mathrm{Mw}$ 8.6 Sumatra earthquake. Science 337, 724-726 (2012).

19. Duputel, Z. et al. The 2012 Sumatra great earthquake sequence. Earth Planet Sci. Lett. 351-352, 247-257 (2012).

20. Satriano, C., Kiraly, E., Bernard, P. \& Vilotte, J. P. The 2012 Mw 8.6 Sumatra earthquake: Evidence of westward sequential seismic ruptures associated to the reactivation of a N-S ocean fabric. Geophys. Res. Lett. 39, L15302 6p (2012).

21. Singh, S. C. et al. Seismic evidence for broken oceanic crust in the 2004 Sumatra earthquake epicentral region. Nat. Geosci. 1, 777-781 (2008).

22. Singh, S. C. et al. Extremely thin crust in the Indian Ocean possibly resulting from Plume-Ridge interaction. Geophys. J. Int. 184, 29-42 (2011).

23. Singh, S. C. et al. Seismic evidence of bending and unbending of subducting oceanic crust and the presence of mantle megathrust in the 2004 great Sumatra earthquake rupture zone. Earth Planet. Sci. Lett. 321, 166-176 (2012).

24. Lizarralde, D. L., Gaherty, J. B., Collins, J. A., Hirth, G. \& Evans, R. L. Structure of Pacific plate upper mantle from active source seismic measurements of the NoMelt experiment. Abstract T33G-2732 presented at 2012 Fall Meeting, AGU, San Francisco, Calif., 3-7 Dec (2012).

25. Ribe, N. M. \& Christensen, U. R. Three-dimensional modeling of plumelithosphere interaction. J. Geophys. Res. 99, 669-682 (1994).

26. Ribe, N. M. \& Christensen, U. R. The dynamic origin of Hawaiian volcanism. Earth Planet Sci. Lett. 171, 517-531 (1999).

27. Carton, H. et al. Deep seismic reflection images of the Wharton Basin oceanic crust and uppermost mantle offshore northern Sumatra: Relation with active and past deformation. J. Geophys. Res. 119, 32-51 (2014).

28. Jacob, J., Dyment, J. \& Yatheesh, V. Revisiting the structure, age, and evolution of the Wharton Basin to better understand subduction under Indonesia. J. Geophys. Res. 119, 169-190 (2014).

29. Pesicek, J. D. et al. Teleseismic double-difference relocation of earthquakes along the Sumatra-Andaman subduction zone using a 3-D model. J. Geophys. Res. 115, B10303 (2010).

30. McKenzie, D., Jackson, J. \& Priestley, K. Thermal structure of oceanic and continental lithosphere. Earth Planet Sci. Lett. 233, 337-349 (2005).

31. Craig, T. J., Copley, A. \& Jackson, J. A reassessment of outer-rise seismicity and its implications for the mechanics of oceanic lithosphere. Geophys. J. Int. 197, 63-89 (2014)

32. Kent, G. M. et al. Evidence from three-dimensional reflectivity images for enhanced melt supply beneath mid-ocean ridge discontinuities. Nature 406, 614-618 (2000)

33. Korenaga, J. Thermal cracking and the deep hydration of oceanic lithosphere: A key to the generation of plate tectonics? J. Geophys. Res. 112, B05408 (2007).

34. Yue, H., Lay, T. \& Koper, K. D. En échelon and orthogonal fault ruptures of the 11 April 2012 great intraplate earthquakes. Nature 490, 245-249 (2012).

35. Stauder, W. Mechanism of the Rat Island earthquake sequence of February 1965 , with relation to island arcs and sea-floor spreading. J. Geophys. Res. 73, 3847-3858 (1968).

36. Chapple, W. M. \& Forsyth, D. W. Earthquakes and bending of plates and trenches. J. Geophys. Res. 84, 6729-6749 (1979).

37. Masson, D. G. Fault patterns at outer trench walls. Mar. Geophys. Res. 13, 209-225 (1991).

38. Ranero, C. R., Phipps Morgan, J., McIntosh, K. \& Reichert, C. Bending-related faulting and mantle serpentinization at the Middle America trench. Nature 425, 367-373 (2003).

39. Fujita, K. \& Kanamori, H. Double seismic zones and stresses of intermediate depth earthquakes. Geophys. J. Int. 66, 131-156 (1981).

40. Zatman, S., Gordon, R. G. \& Mutnuri, K. Dynamics of diffuse oceanic plate boundaries: insensitivity to rheology. Geophys. J. Int. 162, 239-248 (2005).

41. Louden, K. E. Variation in crustal structure related to intraplate deformation: evidence from seismic refraction and gravity profiles in the Central Indian Basin. Geophys. J. Int. 120, 375-392 (1995). 
42. Delescluse, M. \& Chamot-Rooke, N. Serpentinization pulse in the actively deforming Central Indian Basin. Earth Planet Sci. Lett. 276, 140-151 (2008).

43. Kohlstedt, D. L. et al. Strength of the lithosphere: Constraints imposed by laboratory experiments. J. Geophys. Res. 100, 17587-17602 (1995).

44. Geersen, J. et al. Pervasive deformation of an oceanic plate and relationship to large $>\mathrm{Mw} 8$ intraplate earthquakes: The northern Wharton Basin, India Ocean. Geology 43, 359-362 (2015).

45. O'Hanley, D. S., Chernosky, J. V. \& Wicks, F. J. The stability of lizardite and chrysotile. Can. Mineral 27, 483-493 (1989).

46. Escartín, J., Hirth, G. \& Evans, B. Effects of serpentinization on the lithospheric strength and the style of normal faulting at slow-spreading ridges. Earth Planet Sci. Lett. 151, 181-189 (1997).

47. Wunder, B. \& Schreyer, W. Antigorite: High-pressure stability in the system MgO-SiO2-H20 (MSH). Lithos 41, 213-227 (1997).

48. Martinod, J. \& Davy, P. Periodic instabilities during compression or extension of the lithosphere: 1. Deformation modes from an analytic perturbation method. J. Geophys. Res. 97, 1999-2014 (1992).

49. Martinod, J. \& Molnar, P. Lithospheric folding in the Indian Ocean and the rheology of the oceanic plate. Bull. soc. géol. France 166, 813-821 (1995).

50. Kelemen, P. B. \& Hirth, G. A. Periodic shear-heating mechanism for intermediate depth earthquakes in the mantle. Nature 446, 787-790 (2007).

51. McGuire, J. \& Beroza, G. C. A rogue earthquake off Sumatra. Science 336, 1118-1119 (2012).

52. Das, S. \& Scholz, C. H. Why large earthquakes do not nucleate at shallow depths. Nature 305, 621-623 (1983).

53. Garth, T. \& Rietbrook, A. Order of magnitude increase in subducted $\mathrm{H}_{2} \mathrm{O}$ due to hydrated normal faults within the Wadati-Benioff zone. Geology 42, 207-210 (2014).

54. Escartín, J., Hirth, G. \& Evans, B. Strength of slightly serpentinized peridotites: Implications of the tectonics of oceanic lithosphere. Geology 29, 1023-1026 (2001).

55. Hasegawa, A., Umino, N. \& Takagi, A. Double-planed deep seismic zone and upper-mantle structure in the northeastern Japan arc. Geophys. J. R. Astron. Soc. 54, 281-296 (1978).

56. Brudzinski, M. R., Thurber, C. H., Hacker, B. R. \& Engdahl, E. R. Global prevalence of double Benioff zones. Science 316, 1472-1474 (2007).

57. Slancová, A., Špičák, A., Hanuš, V. \& Vaněk, J. How the state of stress varies in the Wadati-Benioff zone: indications from focal mechanisms in the Wadati-Benioff zone beneath Sumatra and Java. Geophys. J. Int. 143, 909-930 (2000).

58. Chauhan, A. P. S. et al. Seismic imaging of forearc backthrusts at northern Sumatra subduction zone. Geophys. J. Int. 179, 1772-1780 (2009).
59. Martin, J. et al. Acquisition of marine point receiver data with a towed streamer. Society of Exploration Geophysicists. Expanded Abstracts ACQ3.3, 37-40 (2000).

60. Lamoureux, M. P. \& Margrave, G. F. A band-limited minimum phase calculation. CREWES Research Report 19, 1-5 (2007).

61. Warner, M. \& McGeary, S. Seismic reflection coefficients from mantle fault zones. Geophys. J. R. astr. Soc. 89, 223-230 (1987).

62. Stein, C. A. \& Stein, S. A model for the global variation in oceanic depth and heat flow with lithospheric age. Nature 359, 123-129 (1992).

63. Brace, W. F. \& Kohlstedt, D. L. Limits on lithospheric stress imposed by laboratory experiments. J. Geophys. Res. 85, 6248-6252 (1980).

64. Chopra, P. N. \& Paterson, M. S. The role of water in the deformation of dunite. J. Geophys. Res. 89, 7861-7876 (1984).

65. Escartín, J., Hirth, G. \& Evans, B. Non-dilatant brittle deformation of serpentinites: Implications for Mohr-Coulomb theory and the strength of faults. J. Geophys. Res. 102, 2897-2913 (1997).

\section{Acknowledgements}

We would like to thank WesternGeco for acquiring and processing the data. Discussions with James Martin helped to improve the seismic image of the DMR1. We would like to thank Javier Escartin for providing the code to compute the differential stress and for discussion on serpentinization. Discussions with Helene Carton were extremely useful. This is an Institut de Physique de Globe contribution number 3660.

\section{Authors contributions}

Y.Q. carried out the low frequency enhancement, processed and analysed the data, and wrote the paper. S.C.S. designed the experiment, participated in the data collection, supervised the processing and the project, and wrote the paper with Y.Q.

\section{Additional information}

Supplementary Information accompanies this paper at http://www.nature.com/ naturecommunications

Competing financial interests: The authors declare no competing financial interests.

Reprints and permission information is available online at http://npg.nature.com/ reprintsandpermissions/

How to cite this article: Qin, Y. \& Singh, S. C. Seismic evidence of a two-layer lithospheric deformation in the Indian Ocean. Nat. Commun. 6:8298 doi: $10.1038 /$ ncomms9298 (2015). 